\title{
EXtrato Etanólico de Senna alata no Controle de Myrothecium roridum, Agente CaUSAl do CanCRo-de-Mirotécio ${ }^{1}$
}

\author{
Ethanolic Extract of Senna alata in the Control of Myrothecium roridum, Causal Agent of \\ Myrothecium Leaf Spot
}

\begin{abstract}
MEDEIROS, E.V. ${ }^{2}$, VIANA, M.G. ${ }^{3}$, ALBUQUERQUE, C.C. ${ }^{4}$, VIANA, F.A. ${ }^{5}$ e SILVA, K.M.B. ${ }^{6}$
RESUMO - O fungo $M$. roridum é o causador da doença cancro-de-mirotécio em meloeiro e vem provocando grandes perdas na produção dessa olerícola. É uma doença de dificil controle, em razão de seu agente ser habitante do solo. Devido à procura de formas alternativas de controle, o objetivo deste trabalho foi avaliar a atividade dos extratos etanólicos de partes de S. alata sobre $M$. roridum. O delineamento experimental foi inteiramente casualizado, distribuído em esquema fatorial $4 \times 6+1$, sendo o primeiro fator partes da planta (caule, inflorescência, raiz e vagem) e o segundo, seis concentrações $(0,25 ; 0,50 ; 50 ; 75 ; 250$; e $500 \mu \mathrm{g} \mathrm{mL} \mathrm{m}^{-1}$ ) mais a testemunha, com quatro repetições por tratamento. As variáveis avaliadas foram: taxa de crescimento micelial (TCM), inibição do crescimento micelial (ICM) e área abaixo da curva do crescimento micelial (AACCM). Todos os extratos de partes vegetais de $S$. alata foram eficientes em inibir o crescimento micelial de $M$. roridum. O extrato etanólico da vagem foi o que melhor inibiu o crescimento de $M$. roridum, na concentração de $500 \mu \mathrm{g} \mathrm{mL}^{-1}$, seguido do extrato da raiz e do caule.
\end{abstract}

Palavras-chave: fungicida vegetal, Cucumis melo, metabólito secundário.

\begin{abstract}
The fungus $\boldsymbol{M}$. roridum is the causal agent of the myrothecium Leaf Spot disease in melon, being responsible for great losses in the production of this olericulture. This disease is difficult to control, since its agent inhabits the soil. Seeking for alternative forms of control, this work aimed to evaluate the effect of the activity of ethanolic extracts of parts of S. alata on $M$. roridum. The experimental design was completely randomized and distributed in a factorial scheme $4 \times 6+1$, with the first factor being parts of the plant (stalk, flower, root and green bean), and the second factor, six concentrations (0.25; 0.50, 50, 75, 250 and $500 \mu \mathrm{g} \mathrm{mL}-1$ ), plus a control, with four repetitions per treatment. The available variables were: mycelial growth rate (MGR), mycelial growth inhibition (MGI) and area below mycelial growth curve (ABMGC). All the extracts of the S. alata parts were found to be efficient in inhibiting mycelial growth of M. roridum. The green bean ethanolic extract was the best inhibitor of the growth of $\boldsymbol{M}$. roridum growth at the concentration of $500 \mu \mathrm{g} \mathrm{mL}$, followed by the root and stalk extracts.
\end{abstract}

Keywords: vegetal fungicide, Cucumis melo, secondary metabolite.

\section{INTRODUÇÃO}

O melão (Cucumis melo) é a principal olerícola produzida no semiárido nordestino. Seu cultivo comercial representa atividade de destaque no setor primário, conquistando espaço cada vez maior nos mercados nacional e internacional (Araújo \& Vilela, 2002). Hoje é considerada a segunda fruta fresca, em volume, mais exportada pelo Brasil (Ibraf, 2010).

1 Recebido para publicação em 11.7.2010 e aprovado em 31.1.2011.

2 Doutora em Fitotecnia, Profa., Universidade Federal Rural de Pernambuco, UFRPE, Unidade Acadêmica de Garanhuns, Av. Bom Pastor S/N, Boa Vista, 55.296-901 Garanhuns-PE, <erika.valente@pq.cnpq.br>; ${ }^{3}$ Mestre em Ciência e Engenharia de Petróleo, $<$ bergvianna@hotmail.com>; ${ }^{4}$ Doutora em Botânica, Profa., Dep. de Biologia, Universidade do Estado do Rio Grande do Norte UERN, <cycavalcanti@gmail.com>; ${ }^{5}$ Doutor em Química, Professor, Dep. de Química, UERN, <arnaldo@yahoo.com.br>; ${ }^{6}$ Doutora em Fitotecnia, Profa. do Dep. de Biologia, UERN, <kmbsbarbosa@yahoo.com.br $>$. 
O aumento dessa demanda - somado à crescente valorização pelos mercados consumidores acerca da uniformidade de produção, quantidade e qualidade do produto trouxe a modernização do sistema de produção com o cultivo intensivo, sem a preocupação com fatores ambientais. As práticas contínuas e intensivas de monocultivo, assim como as constantes mudanças de práticas culturais e ausência de rotação de culturas, têm resultado no aumento do número e severidade de doenças (Medeiros et al., 2006), reduzindo a produção e produtividade.

Nesse sentido, o cancro-de-mirotécio, que tem como agente etiológico o fungo Myrothecium roridum Tode ex Fries, é uma doença que vem ocorrendo com frequência nos cultivos de meloeiro em todo o mundo. Esse fungo foi detectado pela primeira vez no Brasil em 1991, no município de Mossoró-RN (Silva et al.,1996).

A presença do referido patógeno tem limitado a exploração comercial de meloeiro em regiões produtoras no Brasil e no mundo, causando perdas consideráveis tanto em pré quanto em pós-colheita (Mackay et al., 1994). Como esse patógeno possui baixa especificidade por tecido hospedeiro, os sintomas do cancro-de-mirotécio podem ocorrer em várias partes do meloeiro; entretanto, são mais comuns no colo da planta, onde são encontradas lesões alongadas e necróticas, com posterior formação de esporodóquios de coloração verde-oliva (Noronha et al., 2006).

O cancro-de-mirotécio é uma doença de dificil controle, uma vez que $M$. roridum é um habitante natural do solo, podendo sobreviver como saprófita (Viana et al., 2001), e possui ampla gama de hospedeiros (Fitton \& Holliday, 1998).

A utilização de produtos químicos em médio e longo prazo pode ter efeitos desastrosos, como o surgimento de isolados fitopatogênicos resistentes e a poluição do meio ambiente e de lençóis freáticos, motivo pelo qual a utilização de cultivares resistentes (Noronha et al., 2006) e de manejos alternativos (Stangarlin et al., 1999) constitui medida estratégica para o manejo integrado da doença.

Os compostos naturais extraídos de plantas vêm sendo uma alternativa ao uso indiscriminado de produtos químicos no controle de doenças de plantas (Castellanos et al., 2001). Em S. alata, os principais compostos bioativos são taninos, triterpenos, esteroides, alcaloides, carboidratos redutores, flavonoides, saponinas, cumarinas, antocianidinas, emodina, antraquinona, chrysarabina, ribarina, ácido málico, ácido tartárico, ácido crisofânico e um óleo essencial (Ordoñez et al., 2004; Barrese Pérez et al., 2005; Hennebelle et al., 2009). Nessa perspectiva, Senna alata destaca-se entre as espécies com potencial antimicrobiano comprovado (Ibrahim \& Osman, 1995; Somchit et al., 2003), além de ser uma espécie abundante na região potiguar e considerada uma planta daninha (Rodrigues et al., 2009). Essas características favorecem o possivel uso de S. alata como forma alternativa de manejo do cancro-de-mirotécio, representando um método de controle sustentável, pela ação eficaz e, principalmente, por não ser agressivo ao meio ambiente, devido à ausência de resíduos e às suas propriedades biodegradativas.

$\mathrm{Na}$ agricultura, produtos naturais obtidos dos extratos de $S$. alata podem se constituir em uma alternativa para inibição de vários microrganismos responsáveis por perdas elevadas de diversas culturas (Ibrahim \& Osman, 1995; Owoyale et al., 2005), entre eles fitopatógenos habitantes de solo, como é o caso de M. cannonballus (Viana et al., 2008).

Uma das formas de aplicação de um produto natural obtido de $S$. alata no controle de fitopatógenos seria por meio da sanitização de sementes. Segundo Chitarra \& Meyer (2004), o tratamento de sementes pode ser uma medida importante para evitar as podridões e o tombamento de plântulas, reduzindo as fontes de inóculo de $M$. roridum. Embora a transmissão de $M$. roridum não tenha ainda sido comprovada em sementes, esse fungo é isolado com frequência nestas e afeta a germinação e o crescimento de plântulas, como o meloeiro (Lima et al., 1997).

Tendo em vista a crescente busca por formas alternativas de controle de doenças de plantas, o objetivo do presente trabalho foi avaliar o potencial fungicida de extratos etanólicos do caule, inflorescência, raiz e vagem de $S$. alata sobre a inibição do crescimento in vitro do fitopatógeno $M$. roridum. 


\section{MATERIAL E MÉTODOS}

Partes vegetais de S. alata, como caule, inflorescência, raiz e vagem, foram coletadas no município de Rafael Fernandes - RN, pesadas e secas a $65^{\circ} \mathrm{C}$ em estufa de circulação forçada. Após a secagem, as partes vegetais foram trituradas até grau de pó semifino e novamente pesadas, sendo utilizados $40 \mathrm{~g}$ de cada parte para o processo de extração com etanol (Figura 1). Os extratos das diferentes partes do vegetal foram preparados por extração exaustiva com etanol $(3 \times 500 \mathrm{~mL})$ a frio. Após extração, os extratos etanólicos de S. alata foram concentrados em rotavapor sob pressão reduzida, obtendo-se cerca de $1 \mathrm{~g}$ de extrato bruto seco para cada parte analisada. As soluções-estoque de cada parte da planta foram preparadas a partir de $1 \mathrm{~g}$ dos extratos, sendo dissolvidas inicialmente em $50 \mathrm{~mL}$ de etanol e, posteriormente, em $950 \mathrm{~mL}$ de água deionizada estéril, perfazendo uma concentração total de $1.000 \mu \mathrm{g} \mathrm{mL}^{-1}$.

$\mathrm{O}$ isolado de $M$. roridum foi obtido pelo método de plaqueamento (Menezes \& SilvaHanlin, 1997), a partir de planta de meloeiro do cultivar Gold Mine com sintoma de cancrode-mirotécio no colo, coletada de fazenda produtora de meloeiro no Agropolo Mossoró/ Assu.

Fragmentos superficiais desses tecidos vegetais passaram por desinfestação e três lavagens consecutivas com água destilada esterilizada (ADE); eles foram secos e transferidos para placas de Petri contendo o meio de cultura BDA (batata-dextrose-ágar) acrescido de $500 \mu \mathrm{g} \mathrm{mL}^{-1}$ de estreptomicina, as quais foram mantidas a $25^{\circ} \mathrm{C}$ durante sete

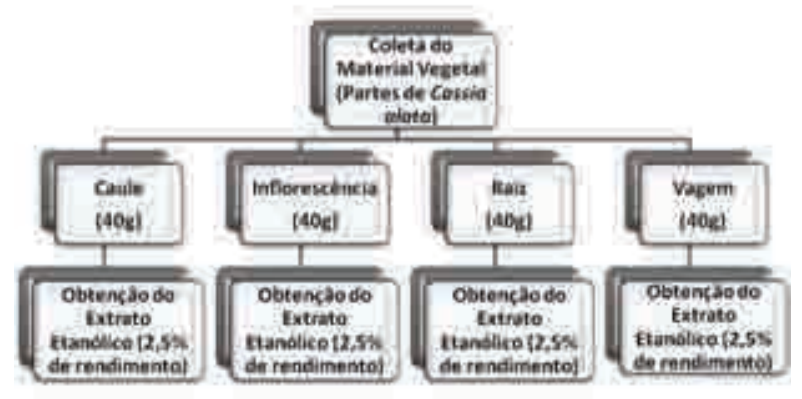

Figura 1 - Fluxograma demonstrando a obtenção do extrato etanólico de partes vegetais de $S$. alata. dias. Posteriormente, os pontos de isolamento foram repicados para cultivos puros, quando foi realizada a seleção de um isolado de M. roridum, cuja identificação foi confirmada por microscopia óptica.

Após a seleção, o isolado foi repicado em culturas puras e incubado por 14 dias em estufa (BOD) a $25 \pm 2{ }^{\circ} \mathrm{C}$, sob alternância luminosa (12 h claro/ 12 h escuro), para obtenção do inóculo.

Os extratos etanólicos das diferentes partes vegetais de $S$. alata foram adicionados nas concentrações de 0,$25 ; 0,5 ; 50 ; 75 ; 250$; e $500 \mu \mathrm{g} \mathrm{mL}^{-1}$, obtidas a partir de série de diluições da solução-estoque - às placas de Petri, juntamente com o meio de cultura BDA. O tratamento controle positivo foi constituído do meio BDA sem extrato.

Discos de $6 \mathrm{~mm}$ contendo $M$. roridum foram retirados de culturas puras com 14 dias e depositados no centro de cada placa de Petri, que foram incubadas a $25^{\circ} \mathrm{C}$ em BOD.

O delineamento experimental utilizado foi do tipo inteiramente casualizado, em esquema fatorial $4 \times 6+1$, sendo quatro tipos de extratos provenientes de diferentes partes da planta e seis concentrações de extratos etanólicos mais a testemunha, com quatro repetições.

As avaliações foram realizadas diariamente por meio de medição do diâmetro das colônias (média de duas medidas perpendiculares), até o total crescimento do tratamento controle. As variáveis analisadas foram: porcentagem da inibição do crescimento micelial calculado pela fórmula de Abbott (1925): $\operatorname{ICM}(\%)=(\mathrm{T}-\mathrm{t})^{*} 100 / \mathrm{T}$, em que $\mathrm{T}$ é a testemunha e t o tratamento; taxa de crescimento micelial (TCM), em milimetro; e área abaixo da curva de crescimento micelial (AACCM), utilizando a fórmula: AACCM $=$ "((yi + yi+1)/ 2. $\left.d_{\mathrm{ti}}\right)$, em que $\mathrm{y}_{\mathrm{i}}$ e $\mathrm{y}_{\mathrm{i}+1}$ são os valores de crescimento da colônia observados em duas avaliações consecutivas e $d_{t i} o$ intervalo entre as avaliações. Para efeito de análise, os dados originais da ICM foram transformados em $\operatorname{arcsen}$ raiz $(\mathrm{x}+0,5 / 100)$ e submetidos à análise de variância, sendo as médias comparadas pelo teste de Tukey a $5 \%$ de probabilidade. Com as médias dos dados brutos, foram obtidas e selecionadas curvas de regressão, tendo as 
concentrações dos extratos como variável independente. Modelos exponenciais, logaritimos, quadráticos e polinomiais foram testados, tendo sido selecionados com base no coeficiente de determinação $\left(\mathrm{R}^{2}\right)$ e no quadrado médio do resíduo $(\mathrm{QMR})$.

\section{RESULTADOS E DISCUSSÃO}

Houve interação significativa entre as concentrações e os extratos etanólicos de diferentes partes da planta. Os modelos polinomiais foram os que melhor descreveram o comportamento das variáveis ICM, TCM e AACCM em função das concentrações (Figuras 2, 3 e 4).

Houve interação significativa $(p<0,05)$ entre as concentrações de extrato e partes da planta na variável ICM (Figura 2). O extrato que melhor inibiu o crescimento micelial de $M$. roridum foi o da vagem de $S$. alata, o qual apresentou ponto de máximo na dose de $500 \mu \mathrm{g} \mathrm{mL}^{-1}$ com inibição de 42,03\%. Nessa mesma dose, o extrato da raiz apresentou média de inibição de $23,14 \%$, e o do caule, em média, 20\%. De acordo com Rodrigues (2010), extratos da vagem de $S$. alata, seguidos dos extratos da folha e da raiz, são considerados as partes que concentram a maior taxa de metabólitos em geral, o que pode justificar a maior taxa de inibição sobre $M$. roridum neste estudo. Entretanto, fatores ambientais, assim como genéticos, podem alterar a concentração de metabólitos, não podendo ser considerada constante a sua distribuição nas diferentes partes da planta (Omoloso \& Vagi, 2001).

Os dados do presente experimento corroboram os de Viana et al. (2008), os quais, avaliando extratos etanólicos das partes vegetais da mesma espécie, observaram também que o extrato da vagem foi mais eficiente em inibir o crescimento micelial de M. cannonballus (a $500 \mathrm{ppm}$ ), fitopatógeno que ataca plantas de melão e habitante do solo, assim como o fungo objeto deste estudo. Frações do extrato etanólico da influorescência

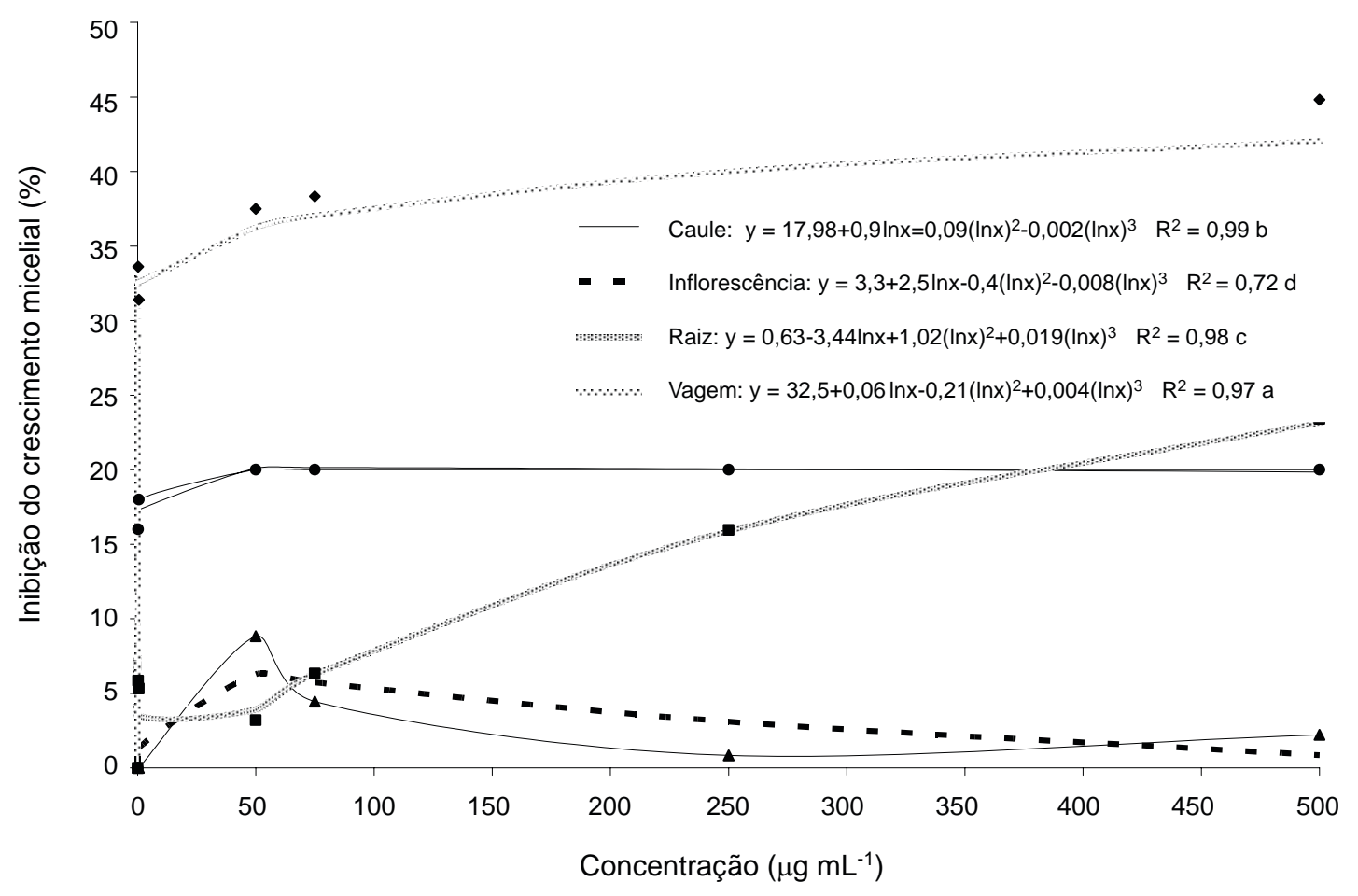

Médias seguidas pela mesma letra nas partes da planta não diferem entre si pelo teste de Tukey a $5 \%$.

Figura 2 - Inibição do crescimento micelial (ICM) de M. roridum em meio BDA acrescido de diferentes concentrações de extrato etanólico do caule, inflorescência, raiz e vagem de $S$. alata 


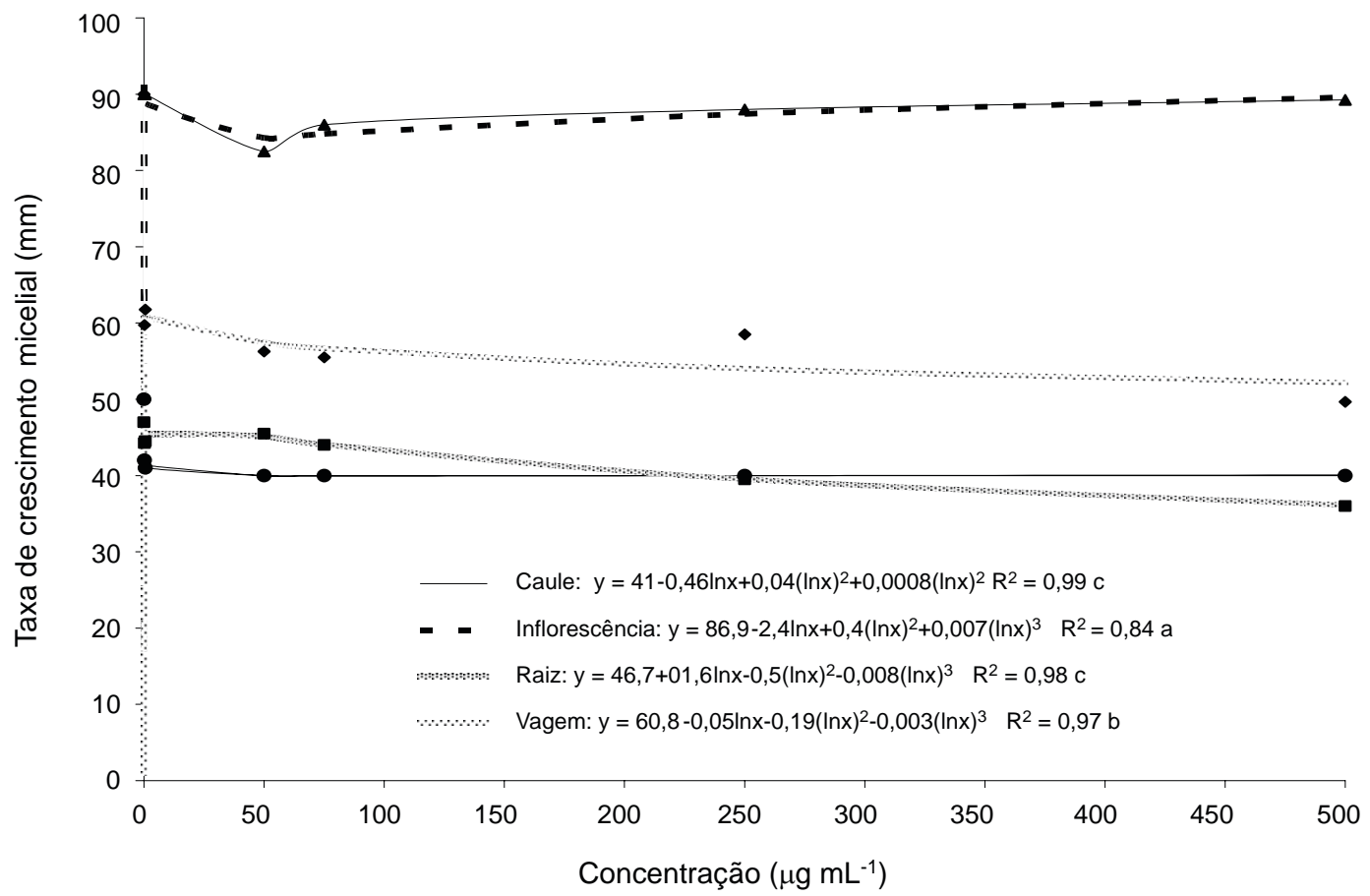

Médias seguidas pela mesma letra nas partes da planta não diferem entre si pelo teste de Tukey a $5 \%$.

Figura 3 - Taxa de crescimento micelial (TCM) de M. roridum em meio BDA acrescido de diferentes concentrações e extrato etanólico de caule, inflorescência, raiz e vagem de $S$. alata.

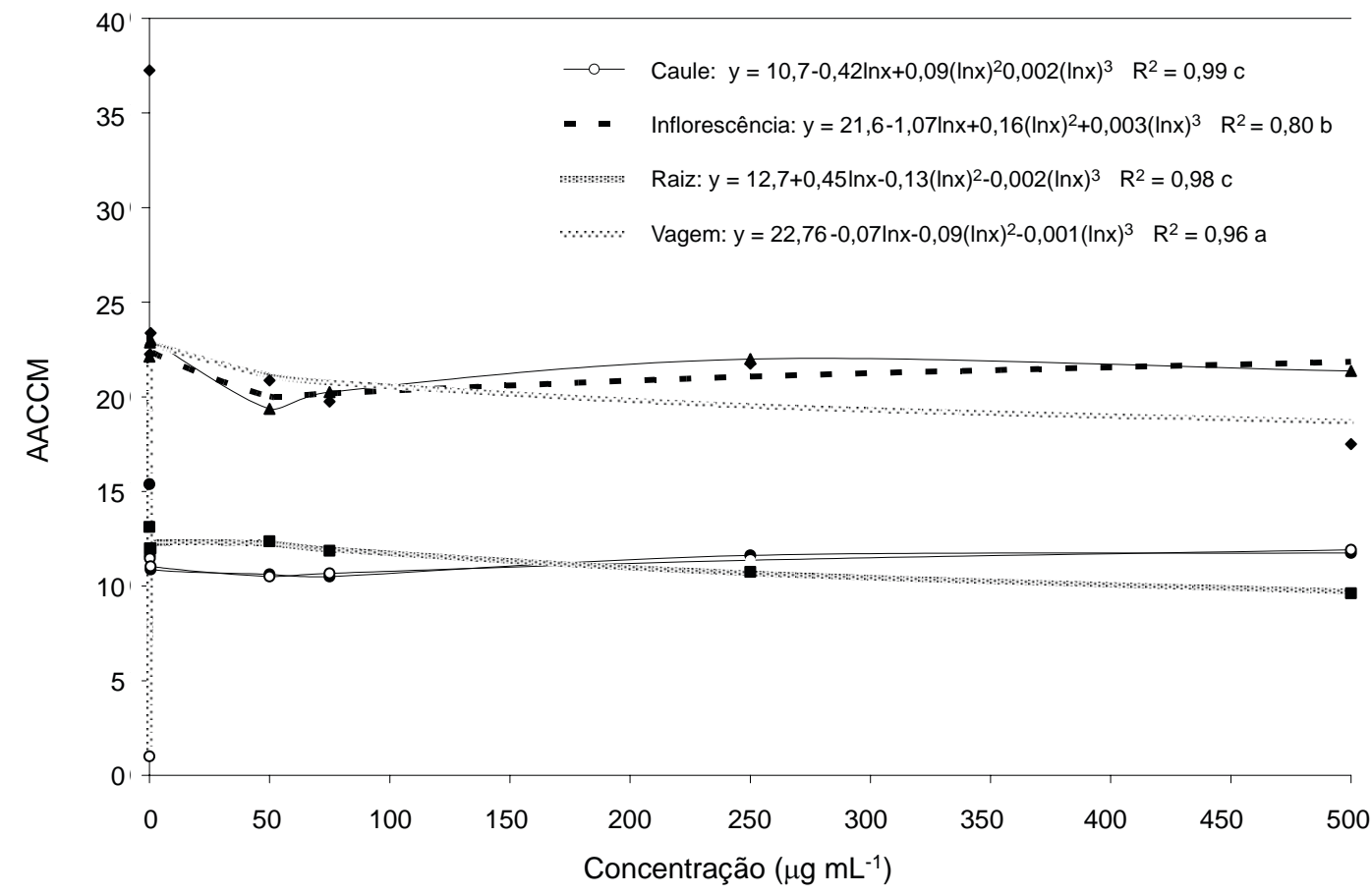

Médias seguidas pela mesma letra nas partes da planta não diferem entre si pelo teste de Tukey a $5 \%$.

Figura 4 - Área abaixo da curva de crescimento micelial (AACCM) de M. roridum em meio BDA acrescido de diferentes concentrações e extrato etanólico de caule, inflorescência, raiz e vagem de $S$. alata. 
de S. alata nesta mesma concentração também foram eficientes em inibir o crescimento de bactérias (Adedayo et al., 2001). Algumas espécies de microrganismos fitopatogênicos, como as dos gêneros Fusarium, Bacillus e Colletotrichum, também tiveram seu crescimento inibido pela ação do extrato etanólico de $S$. alata em concentrações acima de $500 \mu \mathrm{g} \mathrm{mL}^{-1}$ (Makinde et al., 2007; Hennebelle et al., 2009).

O efeito do extrato etanólico da vagem de $S$. alata sobre a ICM de $M$. roridum foi mais eficiente que o de alguns fungicidas comerciais (Silva et al., 2006; Reis et al., 2008). Em experimento in vitro realizado por Reis et al. (2008), avaliando vários fungicidas, verificouse que Daconil, Cerconil, Amístar, Manzate e Manzate $+\mathrm{FeSO}_{4}$ apresentaram ICM menor que $40 \%$ para o isolado de $M$. roridum.

Em relação à TCM, houve interação significativa entre os fatores avaliados (parte da planta x concentração de extrato). As curvas de regressão polinomiais foram as que melhor descreveram o comportamento do fungo diante dessa variável, com coeficientes de determinação variando entre 84 e 99\% (Figura 3).

A AACCM também apresentou efeito significativo para a interação entre as partes das plantas e a concentração do extrato. As curvas polinomiais foram as que melhor se ajustaram para descrever essa interação, com coeficientes de determinação de 99, 80, 98 e 96\% para caule, inflorescência, raiz e vagem, respectivamente (Figura 4).

Assim como na variável TCM, a inflorescência foi a parte da planta que melhor demonstrou aumento da AACCM, com ponto de máximo de 21,86 na dose de $500 \mu \mathrm{g} \mathrm{mL}^{-1}$. Esses dados corroboram os de Viana et al. (2008), os quais afirmam que essa variável explica o comportamento do crescimento do fungo durante todo o tempo de duração do experimento, gerando curvas parecidas, por ambas se referirem ao crescimento micelial.

Todas as partes vegetais do extrato etanólico de $S$. alata mostraram atividade contra $M$. roridum, agente causador do cancro-demirotécio, em todas as variáveis analisadas, e esse fato deve-se, provavelmente, à presença de compostos bioativos nesses órgãos. Esses compostos bioativos são frequentemente sintetizados pelas vias do metabolismo secundário da planta, garantindo a esta um arsenal de compostos químicos de defesa contra diversos fatores bióticos e abióticos.

Visto que os resultados desta pesquisa comprovaram atividade antifúngica de todas as partes vegetais do extrato etanólico de S. alata, reforça-se a necessidade da realização de estudos in vivo para confirmar o potencial antifúngico dos extratos dessa espécie. A comprovação desse potencial no campo seria de grande interesse, uma vez que se buscam alternativas para o desenvolvimento de uma agricultura ecologicamente correta.

\section{LITERATURA CITADA}

ABBOTT, W. S. A method of computing the effectiveness of an insecticide. J. Econ. Entomol., v. 18, n. 2, p. 265-267, 1925

ADEDAYO, O. et al. Phytochemistry and antibacterial activity of Senna alata flower. Pharmac. Biol., v. 39, n. 6, p. 408-412, 2001.

ARAÚJO, J. L. P.; VILELA, N. J. Aspectos socioeconômicos. In: SILVA, H. R.; COSTA, N. D. (Eds.). Melão produção. Brasília: Embrapa Informação Tecnológica, 2002. p. 15-18. (Frutas do Brasil, 33)

BARRESE PÉREZ, Y. et al. Caracterización y estudio fitoquímico de Cassia alata L. R. Cub. Plant. Medic., v. 10, n. 2, p. 1-5, 2005.

CASTELLANOS, P. P. et al. Antifungal activity of the essencial oil of flowerheads of garland chrysanthemum (Chrysanthemum coronarium) against agricultural pathogens. Phytochemistry, v. 57, n. 1, p. 99-102, 2001.

CHITARRA, L. G; MEYER, M. C. Novo e sem controle. Cultivar - Hortaliças Frutas, v. 19, n. 1, p. 16-18, 2004.

FITTON, M.; HOLLIDAY, P. Myrothecium roridum. Bakeham Lane: CABI Bioscience, 1998. 3 p. (IMI Descriptions of Fungi and Bacteria, 253).

HENNEBELLE, T. et al. Senna alata. Fitoterapia, v. 80, n. 7 , p. 285-393, 2009.

INSTITUTO BRASILEIRO DE FRUTAS - IBRAF.

Disponível em: < http://www.ibraf.org.br/estatisticas/ Exporta\%C3\%A7\%C3\%A3o/

ComparativoExportacoesBrasileiras2008-2007.pdf $>$. Acesso em: 31 ago. 2010. 
IBRAHIM, D.; OSMAN, H. Antimicrobial activity of Cassia alata from Malaysia. J. Ethnopharmac., v. 45, n. 3, p. $51-156,1995$

LIMA, G. S. et al. Reação de cultivares de melão a isolados de Myrothecium roridum. Summa Phytopathol., v. 23, n. 2, p. 135-139, 1997.

MACKAY, W. A. et al. Cucumis melo L. callus response to toxins produced by Myrothecium roridum Tode ex. Fries. J. Am. Soc. Hortic. Sci., v. 119, n. 2, p. 356-360, 1994.

MAKINDE, A. A. et al. A. Antimicrobial activity of Cassia alata. African J. Biotechnol., v. 6, n. 13, p. 1509-1510, 2007.

MEDEIROS, E. V. et al. Quantificação de ascósporos de Monosporascus cannonballus em solos não cultivados de caatinga e em áreas de cultivo de melão do Rio Grande do Norte e Ceará. Trop. Plant Pathol., v. 31, n. 5, p. 500-504, 2006.

MENEZES, M.; SILVA-HANLIN, D. M. W. Guia prático para fungos fitopatogênicos. Recife: UFRPE, Imprensa Universitária, 1997. 106 p.

NORONHA, M. A. et al. Reação de genótipos de meloeiro a Myrothecium roridum. Hortic. Bras., v. 24, n. 4, p. 495-498, 2006.

OMOLOSO, A. D.; VAGI, J. K. Broad-spectrum antibacterial activity of Trigonella foenum-graecum. Nat. Produc. Sci., v. 7, n. 1, p. 13-16, 2001.

ORDOÑEZ, M. G. et al. Actividad antimicrobiana de Senna alata L. R. Cub. Plant. Med., v. 9, n. 1, p. 20-25, 2004.

OWOYALE, J. A. et al. Antifungal and antibacterial activities of an alcoholic extract of Senna alata leaves. J. Applied Sci. Environ., v. 9, n. 3, p. 105-107, 2005.
REIS, A. et al. Efeito de fungicidas sobre o crescimento micelial de Myrotthecium roridum. Brasília: Embrapa Hortaliças, 2008. 12 p.

RODRIGUES, I. M. C. et al. Estudo fitoquímico de Senna alata por duas metodologias. Planta Daninha, v. 27, n. 3, p. $507-513,2009$

RODRIGUES, I. M. C. et al. Prospecção química de compostos produzidos por Senna alata com atividade alelopática. Planta Daninha, v. 28, n. 1, p. 1-12, 2010.

SILVA, D. M. W. et al. Ocorrência de Myrothecium roridum em melão em Mossoró, Rio Grande do Norte. Trop. Plant Pathol., v. 21, n. 4, p. 519, 1996.

SILVA, J. C. et al. Fungitoxicidade de grupos químicos sobre Myrothecium roridum in vitro e sobre a mancha-de-mirotécio em algodoeiro. Pesq. Agropec. Bras., v. 41, n. 5, p. 755-761, 2006.

SOMCHIT, M. N. et al. In vitro antimicrobial activity of ethanol and water extracts of Cassia alata.

J. Ethnopharmac., v. 84, n. 1, p. 1-4, 2003.

STANGARLIN, J. R. et al. Plantas medicinais. Biotec. Ci. Desenvol., v. 2, n. 1, p. 16-21, 1999.

VIANA, F. M. P. et al. Recomendações para o controle das principais doenças que afetam a cultura do melão na região Nordeste. Fortaleza: Embrapa Agroindústria Tropical, 2001.

VIANA, M.; G. et al. Avaliação do potencial fungicida de extratos etanólicos de Senna alata contra Monosparacus cannonballus. Ci. Agrotec., v. 32, n. 5, p. 1387-1393, 2008. 